\title{
Alternative Cityscape Visualisation: Drone shooting as a new dimension in urban photography
}

\author{
Murat Germen \\ Sabanci University \\ FASS, 34056, Istanbul, Turkey \\ muratgermen@sabanciuniv.edu
}

\begin{abstract}
I was educated as a city planner and an architect. I am not practising any of these professions anymore due to the fact that they do not offer enough freedom during the process of creation. I later turned into an artist using mainly photography as a visual expression tool and a professional photographer shooting architecture and cityscapes. I always had a deep interest in urban photography, un/consciously referring to my educational past. I kept panoramic photography always in my orbit of most used visualisation apparatuses and techniques, in order to be able to construct more comprehensive urban depictions. Roofs, terraces of skyscrapers, observations decks, towers of any kind have usually been my typical platforms, where I have created a remarkably large collection of global cityscapes. It was and still is too expensive to hire a helicopter for a shoot that does not guarantee a commercial return. While I will keep using the above techniques, I feel like I entered a new era in my professional photography practice as I recently acquired a drone. Drones are not that easy to operate and that affordable to buy, if you intend to go highly professional with hi-res camera bodies on-board. You have to have an operator flying an octocopter and yourself in command of the operator telling him/her where to go and what angle to give, in order to end up with the "right" photograph. I preferred a low-priced quadcopter with a rather lower resolution camera, since I can control both the flying gismo and the camera myself. I can now send my eye to the sky, to a sky tier that I personally call "dronosphere", a layer that is roughly in between $\mathbf{5 0}-150$ metres. This height gives me a particular viewpoint in between street view and map view. This paper will discuss if drone photography can bring a novel visual language to cityscape and / or street photography.
\end{abstract}

Aerial photography. Cityscape. Urban photography. UAV. Drone. Art. Panoramic. Photographic visualisation.

\section{INTRODUCTION - AERIAL PHOTOGRAPHY / AEROPHOTOGRAPHY}

Aerial photography has been around for long, starting to exist short after photography was invented. The initial reasons why it was needed were to provide the necessary visual information for the practices of mapping / cartography, surveying, military reconnaissance, land inspection, providing larger scale urban context information needed for urban and architectural planning, etc.

"Aerial photographs offer a geometrically determined view of objects within a given area. The origins of this view lie in the third millennium BCE, when Sumerian priests ruled city-states through estate management and a religion based on sky gods. [...] Aerial photography began in the mid1800 s, some thirty years after the advent of photography. In 1858 the pioneering Parisian Félix Nadar took a camera on a series of balloon ascents, and in 1864 he published a book about the experience, 'À terre \& en l'air: Mémoires du Géant'. On the other side of the Atlantic, J. W. Black and Sam King ascended 1,200 feet in a balloon to take a photograph of Boston in 1860. It was war, however, that stimulated the development of aerial photography. [...] Kite aerial photography was in fact pioneered by Chicago self-taught photographer and business- man George R. Lawrence in 1906 to capture extra- ordinary wideangle views of the devastation in the aftermath of the San Francisco earthquake" (Hossaini 2006).

Aerial photographs have been / can be taken with a large array of means. Manned hot air balloons, kites, zeppelins / blimps, smaller scale unmanned balloons, airplanes, helicopters, tall buildings, 
satellites and finally unmanned aerial vehicles (UAVs) / drones are among the vehicles, tools and places to create aerial photos with / from. The substitute solution, is to carefully select the proper seat in national and international flights, taking advantage of online check-in feature. I first check the possible course that the plane follows in normal conditions, checking the previous day's flight route information from flightradar24.com and choose left or right window seats accordingly, always away from the wings so that I have a clear view angle with no obstructions.
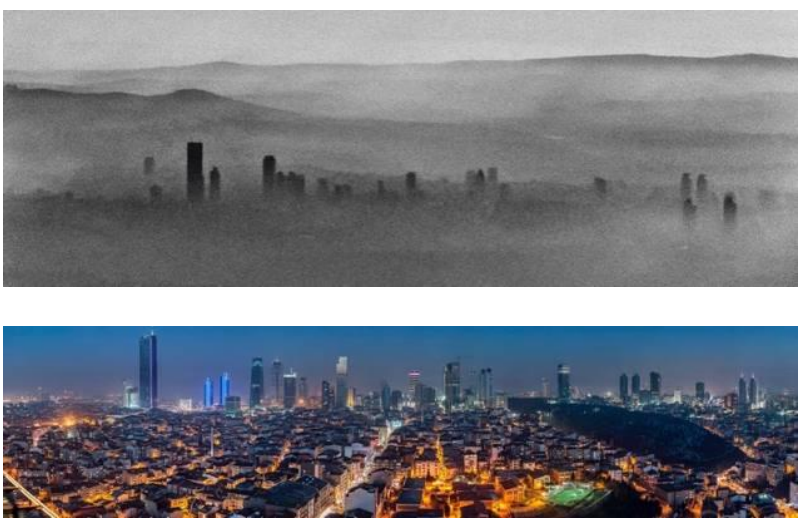

Figure 1\& 2: Istanbul business district from an airplane (up), from a skyscraper (down). Photos: M. Germen.

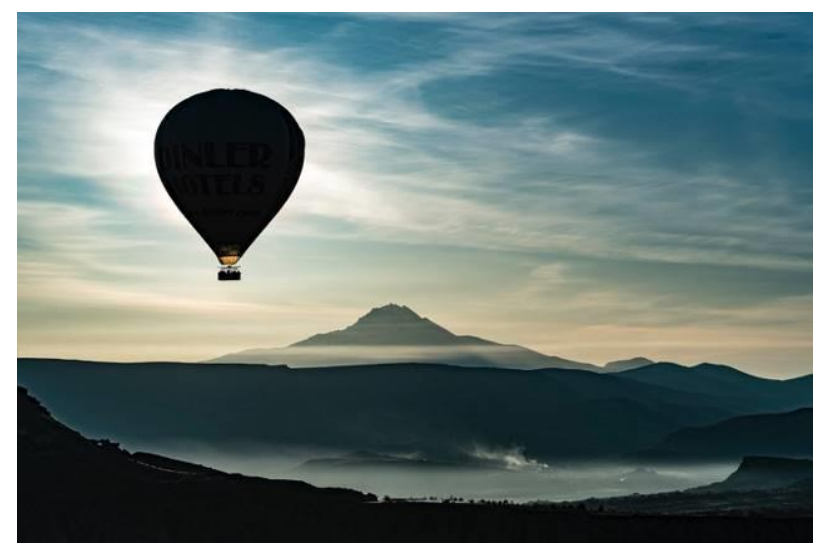

Figure 3: Cappadocia as seen from a hot air balloonPhoto: Murat Germen.

I would like to mention two rather unusual tools some photographers prefer to take aerial photos from relatively closer distances to ground level. The first one is a very tall tripod called megamast that can reach the maximum height of 8,5 metres. Though it is not very quickly operated it has the advantage of being independent of flying vehicles and involved legal permissions to fly. The second one is a "throwable panoramic ball camera" (Pfeil 2011) which has a camera that uses 36 fixed-focus 2-megapixel mobile phone camera modules. The ball, when tossed in the air, captures an image at the highest point of flight when it reaches the inertia point and takes full spherical panoramas. The camera modules are hidden in a robust, 3D-printed enclosure that is padded with foam in order to be able to avoid possible damage after ground impact.

The most conventional utilization of aerial photography is in mapmaking. "Mapmaking took a great leap forward in the early years of the 20th century when aerial photography became possible, and another in the latter half with the advent of satellite imagery and computer technology." (Art of the Map 2014) Online map services like Microsoft TerraServer, Bing Maps, Google Maps \& Earth, Yahoo! Maps, Yandex.Maps, Apple Maps, MAPS.ME (MapsWithMe) are among mapmaking platforms that are accessible by individuals in order to be able to preplan their map-based projects, studies. However, "there are limitations to use of air photography in mapping. It cannot be reasonably expected to do away entirely with the ground work of the surveyor. Rather, the camera is to be regarded as one of the instruments of the surveyor. Observation from the air can never take the place of close examination of the ground, but it can be of great use in the location and study of land forms and geologic relations. Air photography is only an added means of obtaining information, although it promises to become a very important means" (Lee 1922).

In addition to the functional use of aerial photography in areas like cartography, there are exciting deployments of it for artistic intents. "Some artists have joined scientists in the skies, creating portfolios of merit, including the lush, colourful work of French photojournalist Yann Arthus-Bertrand with his massive 'Earth from Above' series. Shown to huge crowds in venues around the world, ArthusBertrand's aerial photography has proven to be a useful tool for ecological awareness." (Hossaini 2006) In addition, check the article titled "Latest Art Trend Is Drone Photography" by Sarah Cascone (2014) - https://news.artnet.com/art-world/latest-arttrend-is-drone-photography-75709)at the globally prestigious art portal artnet.com.

Edward Burtynsky, Andreas Gursky, David Maisel, Jeffrey Milstein, Alex MacLean, Vincent Laforet, Trevor Paglen, Olivo Barbieri, Esteban Pastorino Díaz, Adriel Heisey, Emmet Gowin, Barbara Bosworth, William Garnett, Mario Giacomelli, Miklos Gaál, Aydin Buyuktas are among artists who benefit from aerial photography in order to create their artworks.

\section{ADVANTAGES OF DRONES IN GENERAL AND AS COMPARED TO OTHER AIRBORNE VEHICLES}


Drones has more ability to access previously hardto-reach or otherwise inaccessible places, as compared to the alternative larger airborne vehicles like balloons, helicopters and so on. If the pilot is an experienced one able to manoeuvre the device to very close distances to the subject / object, a drone can offer the potential to open up new territories and reveal previously undetected sites / vantage points, exposing new parts of the world. Drones are less visible, less loud and therefore less detectable, perceptible than helicopters; this can be considered as an advantage in capturing a more candid aerial shot, especially when crowds of people are to be included. Yet another advantage is the fact that you can operate drones within buildings in order to obtain new dimensions in interior architectural photography.

Larger scale airborne vehicles like balloons, helicopters are much more expensive to access than UAVs. With a fraction of the 2-hour renting fee of a helicopter, it is possible to purchase a decent quadcopter. Drones popularize aerial photography by providing access to airborne shooting for many more people, who do not have enough means to hire helicopters preferred by pro-photographers using their much-higher resolution hand held cameras. Now that the notion of resolution is mentioned, one must remember that the relatively affordable drones do not house high resolution built-in cameras. Reasonably priced DJI and similar brands' quadcopter cameras cannot offer the resolution and image quality that some D-SLR cameras and middle format digital bodies can submit. The unmanned aerial vehicles that can carry such hi-res cameras are octocopters and they are not in the category of affordable drones.

\section{DRONES / UAVS' RANGE OF USES - UTILITARIAN PURPOSES}

"Just as manned flight today has far more civilian applications than military, there is a wide array of non-military applications for UAVs: firefighting and disaster recovery, precision agriculture and ranching, pipeline and other utility inspection, weather forecasting, newsgathering, mapmaking, real estate, amateur and professional photography and videography, filmmaking, sports broadcasting, tourism, prevention of poaching and other unwanted behaviours, search and rescue, and shipping and transport" (Blitz, Grimsley, Henderson\& Thai 2015). "Maps that are already widely available from commercial enterprises (e.g., Google Maps) can be augmented with UAV-based data on conflicts, disasters, protests, environmental degradation, labour exploitation, and so forth" (Choi-Fitzpatrick 2014).
Professional journalism, citizen journalism, human rights monitoring, environmental change observation for managing threatened natural areas, search-and-rescue operations, mapping the spread of hostile species, monitoring out-of-the-way park locations, humanitarian and development aid under the form of food / medicines delivery to disaster areas are actual and prospective fields at which drones are / can be employed. To give specific examples, "UAVs are deployed to augment the support of traditional ambulance or rescue services, as in the case of an accident in which a small UAV, equipped with a thermal imaging device, was able to locate a wrecked vehicle in Canada, and another in which a camera-equipped drone located a man whom rescue workers had been unable to find for days. Yet such efforts fall into a regulatory grey zone, a fact further complicated by the commercial availability of a weaponised 'riot control copter' for use against protesters" (Choi-Fitzpatrick 2014). In the latter sense, i.e. when drones are used for surveillance, it is possible to alternatively define the drone as a telematic panoptic device. When not used by the security forces, but instead by pro-human rights activists monitoring brutal police action, drones may be perceived as dangerous devices to be terminated. Police in Istanbul shot a cameraequipped UAV down, while it was monitoring police violence that caused the death of 8 people during the anti-government protests in Gezi Park resistance.

In addition to above mentioned functional practises; small scale package delivery conceived by Amazon and Google, internet services to be delivered with the aid of drones (Google and Facebook are working on this idea), real estate projects' promotion, professional wedding documentation, 3D mapping by shooting hundreds of stills in order to be able to have visual data to build a 3D map in the computer environment are other projects / ideas / platforms for which commercial and noncommercial actors use UAVs for public and private objectives.

\section{DRONES / UAVS' RANGE OF USES - ARTISTIC PURPOSES}

Technology and art have long been partners and complementary areas of creative production. Artists have always followed the advances in technology in order to be able to explore novel languages of expression, by experimenting with what innovations physically and intellectually can offer them, both during the inspiration and creation processes. Artists have not only taken advantage of what machines, tools, techne offer them ideally by producing "perfect" results; but also benefited from the serendipitous consequences of failures 
performed by machines and software running them, as creativity is a stochastic process (Please see the author's article titled "Aesthetics of serendipity: Muta-morphosis" published in the International Journal of Art, Culture and Design Technologies (IJACDT), Vol.1, No.2, 25-37, 2011).

This is why many artists and visualisation professionals, started to experiment right after drones were introduced to the market, to see what they could offer in differentiating creative expression. A unique project that involved the use of a drone as a tool of artistic creation, is KATSU's "Dronescapes" series. KATSU is an artist who lives and works in Brooklyn, New York; in his works, he questions contemporary issues like commercialism, technology, privacy in digital culture. Together with FAT Lab member, Becky Stern, they developed a quadcopter they called the Graffiti Drone, that introduced a demountable and remotely controllable spray can that let him paint whilst the device flew. "The drone is capable of spraying canvases or walls hundreds of feet high, granting the artist access to physical spaces that were previously inaccessible" (Michel2014).

Another exceptional art project using drones is executed by the Italian artist group IOCOSE and entitled "Drone Selfies". The project exhibits UAVs photographing themselves in front of mirrors, referring to the selfie-obsessed people nowadays. Filippo Cuttica, a member of IOCOSE, states in an interview that they "really wanted to shift this human centred point of view towards a dronecentric perspective. In our project the drone's camera is pointed towards a mirror, as in the 'human' selfies, rather than at another human being (the drone's 'master', presumably). What would drones do, if they did not have to 'serve' human beings?" (Nunes 2014)

While the above mentioned "Drone Selfies" project refers to the almost narcissistic tendencies of people in the public, a project named "Drone boning" stands out as a drone-shot pornographic film raising the issues of privacy in the open air. Brandon LaGanke, one of the Brooklyn-based filmmakers behind 'Drone Boning' told Jason Koebler, for his article titled 'This Drone-Shot Porn Is Beautiful' that they "wanted to explore the whole idea of drone privacy and strikes-this idea of 'make porn, not war'. It started as a kind of funny commentary on privacy and voyeurism, but it quickly became a conceptual grounding"(Koebler2014).

Drones can be incorporated within art projects not only during the process of creation but also at the viewing stage following the completion. I was recently in Cappadocia region of Turkey in order to do documentary photography for my artwork to be displayed at the Cappadox Festival in May 2016. One of the off-mass-tourism destinations I wanted to document was Andrew Rogers' artworks that were spread on hills near Avanos, Cappadocia. Andrew Rogers is a contemporary artist born, 1947, in Australia and the creator of one of the largest land art enterprises forming a chain of 14 sites all around the world, unprecedented in its scale and ambition. His project titled "Rhythms of Life" comprises monumental geoglyphs (started to be constructed in 1998) that link various symbols derived from ancient rock carvings to local memory and heritage.

Though I took photos of these impressive artworks from the ground level, I decided to fly my drone as well since I thought the most appropriate photos of these works could only be produced from the sky. Alternative to many single photos I shot, I also took multiple photos tilting drone's camera vertically in small increments, with the aim of stitching a vertical panorama that would display multiple perspectives ranging from totally downward aerial to not-titled regular camera positions. The final stitched image reduces many gazes into a unique solo gaze that cannot be obtained by naked eye / single photo. Same unique photographic description can also be seen in the subsequent documentary image of German artist Heinz Mack's installation labelled "The Sky Over Nine Columns" at the Sakip Sabanci Museum, Istanbul.
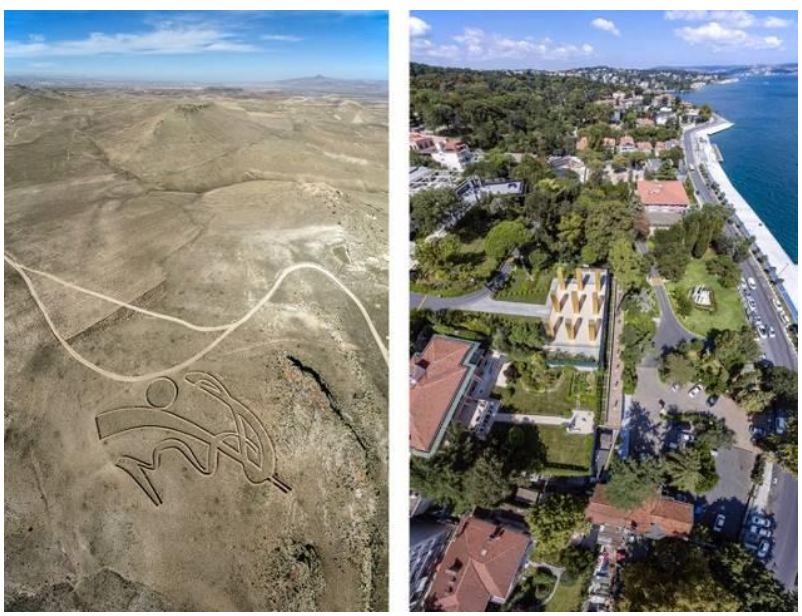

Figure 4 \& 5:Andrew Rogers' artwork (left), Heinz Mack'sartwork (right). Photos: M. Germen.

Perspectivism, a notion coined by Friedrich Nietzsche, can be metaphorically contextualised at this point. The particular concept refers to the discernment that there are many possible intangible perspectives from which constructions of truth can be made. Though the visualisations above are impossible to the naked eye and therefore not "true" in the very crude sense, the holistic information they hold does not include any component that were not there at the time multiple 
photos to be stitched were taken. One must remember that photographs have always been composed from the perspective of the person behind the camera, as the camera does not wander around like a flâneur and take photos by itself. The person's POV (point of view) photography is all about him / her, and not a collective conscious; though inauspiciously presented like this.

Though Amir Soltani (2013) states that "blind stitching [of aerial images] using automated methods instead of manual stitching can also cause faultiness in the final representation," the author's rather customised vertically panoramic aerial visualisations shown above, are not created with the intention of presenting idealised visual fidelity. They instead reflect the distinct perspectival stacking hierarchy that the photographer prefers to reach. In this sense, these aerial portrayals can be likened to some Ottoman miniatures that depict urban scenes, drawn in an optical projectional style that is in between map / plan drawing and resembles isometric perspective: Top is more distant and bottom is closer to the viewer. The specific viewpoint in between street view and map view, obtained from sky tier that the author referred to as "dronosphere" (an altitude layer of $50-150$ metres from ground), brings a more recognizable perspective to aerial photography as opposed to only map view. It additionally offers the advantage of being able to read preliminary clues about the plan layout of neighbourhoods, though not as accurate as a map obviously. So, this interim visuality is able to accommodate more clues, details about an urban scene, as compared to only map view or the street view. In addition, vertical panorama making process leads to another technical advantage in the presence of rather lowresolution (12 MP for DJI Phantom 3 \& 4 models) built-in cameras: More pixels to work with.

In addition to the vertical aerial panoramas, I correspondingly produce the good old horizontal panoramas from the dronosphere. Having been educated as a city planner and architect, my work regularly focuses on social, political, economic, cultural landscapes in urban milieus and circumstances. "Landscape can be seen, as it was in 19th-century debates, as a general name for substances - it can mean bricks and mortar, leaves and fields, the desert, automobiles on a street, overcast or sunny skies, rural and suburban trees, concrete architecture, ghettos, a seascape at night, a seaside resort, the post-conflict rubble of a wartorn city, a tourist resort, industrial spaces, interiors or panoramic views. 'Landscape' is not all things to all people, but a highly differentiated discourse on representing space." (Bate 2009) The horizontal panoramic work is centred around documentation of the shocking consequences of exaggeratedly massive urbanization that is being conducted by the ruling government in Turkey, in order to deceitfully save about-to-collapse economy. The corpus of photos will lead to a collective urban diary that will be used to show how cities once used to look like in Turkey and prove the massive loss of historical, cultural, social heritage to the next generations. Picturing the damaged and vanished landscape involves an investigation of the tension in between vulgarly harsh gentrification and memories of previously progressive approaches that are consciously erased in order to declare dictatorship of conservative impositions. After all, "altered photography is a postmodern tool for presenting the postmodern world" (Ohlin 2002).
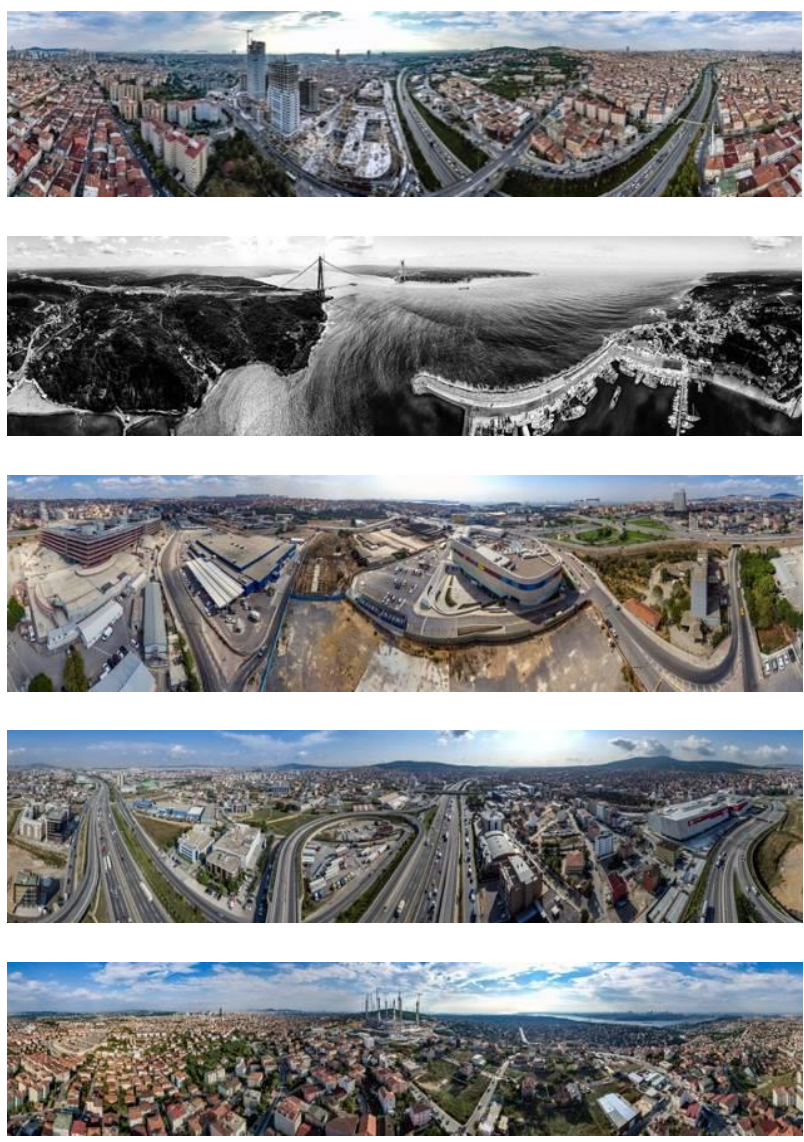

Figure 6, 7, 8, 9\&10:Aerial panoramic photos, taken with a DJI Phantom 3Professional, from the intense urbanization areas of Istanbul.Photos: M. Germen.

Panoramic images have a self-proclaimed aura as they are more inclusive as opposed to single images and are more compatible with human vision by denoting perception spread over time. David Bate, an artist and writer based in London, describes this actuality very astutely: "The panoramic -panoptic- view offers a kind of mastery over the scene and, by implication, over 'nature' itself. Like a child in front of a cake too big to digest, the panorama is impossible to eat or digest, thus it is satisfying and dissatisfying in terms of the aim of seeing. The panorama is 'magnificent', both picturesque and sublime. The viewer is as much 
absorbed in the technological feat of the representation as the scenes they have seen" (Bate 2009).

Another personal project I would like to mention here is titled "Touch forever", which is a portrait study carried out with a drone. During the drone shoots, my wife Sema assists me by keeping an eye on the drone while I focusedly keep my eye on the iPad I use as a preview screen. She watches where the drone is going and if there is a possible obstacle around to avoid. Her final task is to hold, embrace the drone just before touchdown, since not all terrains are suitable for landing. I started to photograph her during this final task that I call embracing; it felt as if I was reaching, touching her after a break.
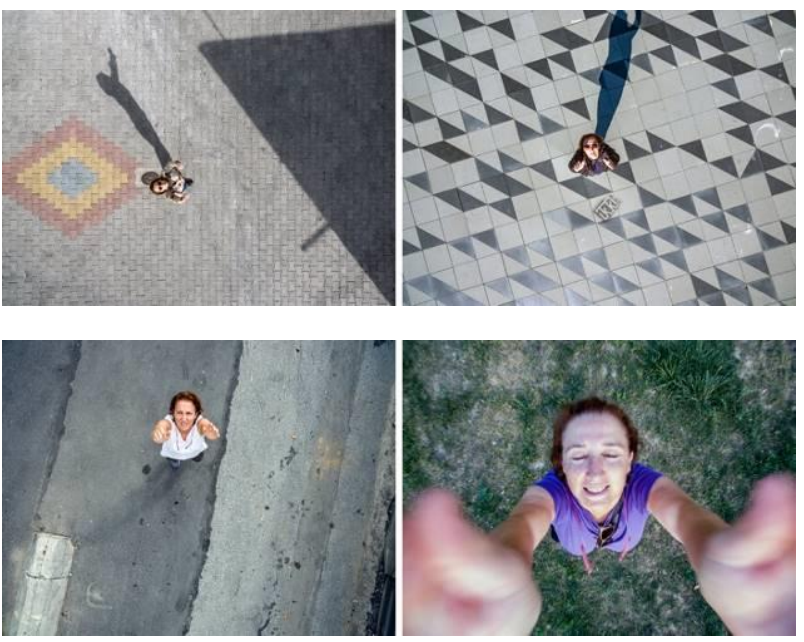

Figure 11, 12, 13\&14: Works from the "Touch forever" series taken with DJI. Photos: M. Germen.

Finally, "in the hands of photographers or filmmakers, drone image capture might become artistic expression; in the hands of journalists, or others commenting on public affairs, it might become a part of public discourse. Even when drone surveillance seems disconnected from such artistic or political expression, First Amendment values may be offended when government bars drone image capture in order to silence the speech that capture makes possible" (Blitz, Grimsley, Henderson\& Thai 2015). This statement leads to a suitable ground to provide some details about the law and privacy matters related to the use of drones.

\section{LEGAL ISSUES TO CONSIDER DURING THE USE OF DRONES AND PRIVACY ISSUES}

Since I am not a professional specialized in law, most of this section will be composed of quotes from the experts. Below are the excerpts from an article titled "A Fair Flight: Drone Photography and the Law" found in Lynda.com, a Linkedln company, known for being as one of the most comprehensive software tutorials resources (Wright2015).

"Recreational uses of drones: Fortunately, a photographer who uses a drone only for hobby or recreational purposes doesn't need FAA approval, as long as:

- your UAV is less than 55 pounds,

- you operate the UAV in a way to not interfere with any manned aircraft

- you give an airport operator prior notice if you plan to fly the UAS within 5 miles of an airport, and

- you fly the UAV within your line of sight.

Commercial uses of drones: If you're using your UAS for commercial purposes, then you first need approval from the FAA to avoid civil penalties. The FAA considers "commercial use" of UAS flights as those in connection with a business, including:

- $\quad$ selling photos or videos taken from a UAV,

- using a UAV to provide contract services, such as for industrial equipment or factory inspection, and

- using a UAV to provide professional services, such as for security or telecommunications purposes."

"One could perhaps argue that First Amendment protection for image or video capture should be limited to those images and videos that count as photographic or other artistic expression. Under this view, when drone cameras capture images or video footage for use in a nature documentary, a travel video, or even a personal photo album or YouTube video, they would receive First Amendment protection." [...] "Image capture would count as First Amendment activity only when it is part of photography or some other conventional means of artistic or other expression, but not when it is simply a means of gathering information. [...] Video creation is protected because it is an indispensable step in the process by which news organizations, civic-minded individuals, or others document and share with the broader public what happens in the nation's public life. Drone video capture is thus covered by the Seventh Circuit's argument that free speech law must protect the process of producing speech, and not simply the resulting speech itself" (Blitz, Grimsley, Henderson \& Thai 2015).

"Drone usage for the public good, it is argued, should prioritize 1) subsidiarity; 2) physical and material security; 3) the 'do no harm' principle; 4) the public good; and respect for 5) privacy, and 6) data" (Choi-Fitzpatrick 2014). Though there are various bills in the US pursuing the limitations of UAVs usage, official authorities have different 
approaches: "California governor Jerry Brown has vetoed a Senate bill that sought to make it illegal to fly a drone less than 350 feet above someone's private property without their permission" (Zhang $2015 b)$. Even if the general use of drones is to be banned you'll find that there will be a number of exceptions: "(1) with permission of the owner/occupant of the property in the photo, (2) with a legal warrant, (3) by law enforcement, (4) for fire and/or rescue operations, (5) without magnification from no more than 6 feet above ground, and (6) on public land" (Zhang 2015a).

In addition to concerns on safety and legislatory control, privacy issues have to be acknowledged. The existence of drones is certainly not the first occasion people brought privacy concerns into discussion. Since the introduction of telephoto lenses, independent photographers called paparazzi unaffiliated with mainstream media organizations, have long been violating the privacy of public figures and celebrities in order to provide material for the tabloid press. Closed-circuit television (CCTV) cameras record people every single day without their permission for the excuses of security. The British Security Industry Authority (BSIA) estimated Britain has a CCTV camera for every 11 people in year 2013 and number of CCTVs is increasing due to the global nature of terrorism that can take anywhere at anytime. There are many people who complain about the fact that CCTVs violate personal privacy. Webcams broadcasting live video feed are also criticized from time to time for the same reason. About a decade ago, Sony of Japan introduced a home video camera equipped with night vision capability, using infrared technology that allowed users to take pictures in pitch dark. Someone experimenting with the camera, discovered that using night vision feature with a special filter in broad daylight allows the viewer to see through some clothes. The discovery and its possible unpermitted use for voyeurism blazed the debate on personal privacy in the public.

Specially produced cameras mounted on cars (in roads) and people (in pedestrian streets) used in Google Street View program take photos without getting model releases from people automatically included during the shoot. Some people who were concerned about their privacy or dreamed of big lawsuit money, sued Google for violation of privacy. Following these court cases Google started to blur the faces of people in order to avoid compensation for alleged material and moral damage. Not all people sue Google; on the contrary, some individuals or groups of people learn the timing of the Google Street View shooting session beforehand and organize small scale protests, publicity events to be recorded and memorialised by Google. Michael Wolf, a leading German photographer, took advantage of Google Street View photographs with the purpose of creating his own appropriated photos taken from his computer screen and won a World Press Photo honourable mention documentary award. The launch of ubiquitous smart phones enabling people to take photos quickly and secretly, while pretending to use apps is yet an additional zone of agnosticism, scepticism, distrust vis-à-vis intrusion into private lives. Constant connectivity of these communication apparatuses is even a more worrisome dimension of smart phones' potential violation of intended isolation.

Above examples are not given to legitimise the presence of drones. UAVs self-evidently carry the potential of being misused for unacceptable, unlawful visual trespassing. Yet, abuse of technology for violation of privacy is not restricted to drones and telephoto lenses used on ground level are usually more effective for spying (please see Adam Derewecki's experiment "Are Drones Better Than Telephoto Lenses for Spying? The Answer May Creep You Out" (Derewecki 2015).

\section{CONCLUSION}

Technological advances provide the necessary grounds for evolution in artistic practice. Invention is technology's inspiration for creativity; borrowing and appropriating are art's inspirations for creativity. I personally follow the emerging apparatuses and related developments in the know-how of their various practises. New software features / settings added to camera bodies, new lenses offering new angles and capture types, new software editing / correcting / enhancing photography, new image recording devices augmenting the way we easily document what we want to share, have always been in my orbit of interests; provided that I can personally afford them. Thus, it was unavoidable for me to stay away from experimenting with a drone.

Most my work focuses on cities and how they develop by keeping or losing their intrinsic characters. "Cities, unlike villages and small towns, are plastic by nature. We mould them in our images: they, in their turn, shape us by the resistance they offer when we try and impose our own personal form on them" (Raban 1974). Various angles, perspectives immersed in my multifaceted contemplation towards the cities help me in conveying a more comprehensive visual story telling. With the freedom of selecting almost any spot in space to shoot from and the resulting unusual vantage points that drones offer me; I feel like I have more to say, to add to what I previously said. If we briefly define Barthes' concept of studium as an element that creates interest in a 
photographic image, I believe drones are capable of bring studium within photos, just due to the very simple fact that they provide an atypical angle. The existence of a punctum, is as usual, up to the photographer's skills.

Protecting privacy is of prime importance; yet, so are shedding light on undiscovered areas, generating new discourse, expanding visualisation styles. I already started to see the UAV as a prosthesis that augments, enhances, diversifies the way I produce my artistic and professional work. I dream of solar-powered drones...

\section{REFERENCES}

Bagley, J. W. (1941) Aerophotography and Aerosurveying.McGraw-Hill, New York.

Bate, D. (2009) Photography: The Key Concepts.Berg, New York.

Bjornstad, R. (2014) Art of the Map. The RegisterGuard Newspaper (Eugene, OR), April 6.

Blitz, M. J., Grimsley, J., Henderson, S. E., and Thai J. (2015) Regulating Drones under the First and Fourth Amendments. William and Mary Law Review, 57(1).

Cascone, S. (2014) Latest Art Trend is Drone Photography. https://news.artnet.com/artworld/latest-art-trend-is-drone-photography-75709 (retrieved 20 March 2016).

Choi-Fitzpatrick, A. (2014) Drones for Good: Technological Innovations, Social Movements, and the State. Journal of International Affairs, 68(1), Fall-Winter.

Derewecki, A. (2015) Are Drones Better than Telephoto Lenses for Spying? The Answer May Creep You Out.

http://petapixel.com/2015/08/21/are-drones-betterthan-zoom-lenses-for-spying-the-answer-maycreep-you-out/ (retrieved 20 March 2016).

Hossaini, A. (2006) Aerial Photography. Lynne Warren (eds), Encyclopedia of Twentieth-century Photography. Routledge, Taylor \& Francis Group, New York.
Koebler, J. (2014) This Drone-Shot Porn is Beautiful.http://motherboard.vice.com/read/the-firstdrone-shot-porn-is-beautiful-nsfw (retrieved 20 March 2016).

Lee, W. T. (1922) The Face of the Earth as Seen from the Air: A Study in the Application of Airplane Photography to Geography. American Geographical Society, New York, USA.

Michel, A. H. (2014) The Drone that will Change Graffiti: An Interview with KATSU. http://motherboard.vice.com/read/the-graffiti-dronean-interview-with-katsu (retrieved 20 March 2016).

Nunes, A. (2014) Now even Drones are Taking Selfies.

http://thecreatorsproject.vice.com/blog/now-evendrones-are-taking-selfies (retrieved 20 March 2016).

Ohlin, A. (2002) Andreas Gursky and the Contemporary Sublime. Art Journal, 61(4), pp. 2235.

Pfeil,J.(2011)Throwable panoramic ball camera. http://jonaspfeil.de/ballcamera (retrieved 20 March 2016).

Raban, J. (1974) Soft City.Collins Harvill, London.

Soltani, A. (2013) Embodied Airborne Imagery: Low-Altitude Cinematic Urban Topography. Electronic Visualisation and the Arts (EVA 2011), London, 6-8 July, pp. 39-55. Springer, LondonHeidelberg-New York-Dordrecht.

Wright, C. E.(2015) A Fair Flight: Drone Photography and the Law.

http://www.lynda.com/articles/drone-photographylaws (retrieved 20 March 2016).

Zhang, M. (2015a) Arkansas Bill Criminalizes Capturing and Possessing Certain Camera Drone Photos. http://petapixel.com/2015/01/16/arkansasbill-criminalizes-capturing-possessing-certaincamera-drone-photos/ (retrieved 20 March 2016).

Zhang, M. (2015b) California Governor Vetoes Bill that Banned Drones over Private Property. http://petapixel.com/2015/09/11/california-governorvetoes-bill-that-banned-drones-over-privateproperty/ (retrieved 20 March 2016). 